\title{
AUTOBIOGRAFIA E CURRÍCULO
}

\section{HILLER SOARES SANTANA}

https://orcid.org/0000-0003-2579-1390

RESUMO

\section{ABSTRACT}

Este artigo apresenta algumas considerações a respeito da opção metodológica da autobiografia, utilizada como defesa de tese de doutoramento em Educação, no campo do currículo, inspirada no Método Currere de William Pinar (1996). Discuto aqui, ainda que de forma sintética, a forma utilizada no texto da tese, como uma imitação de texto teatral, bem como apresento as bases do método que subsidiaram a escrita autobiográfica. 0 artigo considera outras influências, mas enfatiza a perspectiva apresentada pelo método proposto por Pinar como sendo a que foi apropriada efetivamente para a inscrição de minha biografia na cena curricular.

Palavras-chave: Autobiografia. Método Currere. Currículo. Gênero e sexualidade.

\section{AUTOBIOGRAPHY AND CURRICULUM}

This article presents some considerations about the methodological option of autobiography, used as a defense of doctoral thesis in Education, in the curriculum field, inspired by William Pinar (1996) Currere Method. I discuss here, albeit synthetically, the form used in the thesis text, as an imitation of theatrical text, as well as presenting the basis of the method that subsidized autobiographical writing. The article considers other influences, but emphasizes the perspective presented by the method proposed by Pinar as the one that was actually appropriate for the inscription of my biography in the curricular scene.

Keywords: Autobiography. Currere Method. Curriculum. Gender and sexuality.

\section{AUTOBIOGRAFÍA Y CURRICULUM}

Este artículo presenta algunas consideraciones sobre la opción metodológica de la autobiografia, utilizada como defensa de una tesis doctoral en Educación, en el campo del currículo, inspirada en el Método Currere de William Pinar (1996). Discutir aquí, aunque de manera sintética, la forma utilizada en el texto de la tesis, como una imitación del texto teatral, así como presentar la base del método 
que apoyó la escritura autobiográfica. El artículo considera otras influencias, pero enfatiza la perspectiva presentada por el método propuesto por Pinar como la que fue efectivamente apropiada para el registro de mi biografía en la escena curricular.

Palabras clave: Autobiografia. Método Currere. Currículo. Género y sexualidad.

\section{Inscrevendo minha biografia no currículo}

Meu "infinito particular"

Eis o melhor e o pior de mim

O meu termômetro o meu quilate

Vem, cara, me retrate

Não é impossivel

Eu não sou dificil de ler

Faça sua parte

Eu sou daqui eu não sou de Marte

Vem, cara, me repara

Não vê, tá na cara, sou porta bandeira

de mim

Só não se perca ao entrar

No meu infinito particular

Em alguns instantes

Sou pequenin@ e também gigante

Vem, cara, se declara

O mundo é portátil

Pra quem não tem nada a esconder

Olha minha cara

É só mistério, não tem segredo

Vem cá, não tenha medo

A água é potável

Daqui você pode beber

Só não se perca ao entrar

No meu infinito particular

Infinito Particular. ${ }^{1}$

Compositores: Arnaldo Antunes, Marisa Monte, Carlinhos Brown (2006)

Em maio de 2019 defendi como tese de doutoramento uma autobiografia curricular².

1 Letra de música pertencente ao Álbum homônimo: Infinito Particular. Marisa Monte. 2006. Disponível em: https://www.vagalume.com.br/marisa-monte/infinito - particular. Acesso: em 23/07/2018.

2 Para os que estejam interessados na leitura da tese, o link do texto é: http:// www.bdtd.uerj.br/tde_busca/ arquivo.php?codArquivo=15992
Nela, apresento questões surgidas a partir de vivências minhas no cotidiano escolar, entendidas como curriculares e reflito sobre os sujeitos rompentes da heteronormatividade entre os quais eu me incluo - para, a partir de pesquisas realizadas, apresentar uma arena discursiva na qual estão presentes a aceitação e a repulsa aos sujeitos não heterossexuais nos espaços escolares e, com esses registros questionei a "naturalidade" da violência e da discriminação aos indivíduos LGBTQ+3 .

A letra da canção dos Tribalistas, que usei acima como epígrafe, além de identificar um eu-lírico aparentemente do gênero feminino grafado no adjetivo "pequenina" que eu, com liberdade poética, represento com “@” tentando retirar a fixação de gênero - tem importância porque demonstrar o quanto nossos "particulares" podem ser infinitos, independentemente dos gêneros que assumimos como sujeitos sociais. Essa percepção é pertinente para justificar a opção metodologia da autobiografia com a qual defendi a minha tese de doutoramento em educação, numa perspectiva curricular, por entender que todas as vivências que temos no decorrer de nossas vidas e

3 LGBTQ+é a sigla semelhante as siglas LGBT, LGBTT'S e a contemporânea LGBTI que representa o movimento de Lésbicas, Gays, Bissexuais, Transgêneros ou intergêneros (I). A letra $Q$ de Queer seguida do sinal + estão ligados a uma perspectiva acadêmica que compreende uma série de empreendimentos na sociologia, nos estudos culturais, na antropologia, na filosofia, nas artes e em diversos outros campos do saber, no sentido de afirmar essas identidades da diferença. 
consequentemente os efeitos delas decorrentes, vão construindo aquilo que reconhecemos como nossas identidades, que se constituem na hibridização cultural entre experiências pessoais e alheias, ou seja, no diálogo entre os sujeitos da diferença, que com convicções e crenças distintas constroem, contingencialmente, o que considero uma identidade forjada na impossibilidade de fechamento de sentidos e de significações. Uso a metodologia autobiográfica para defender que as identidades são, a meu juízo, construções discursivas.

O meu objetivo com este texto é apresentar o método currere como possibilidade autobiográfica de um currículo vivido como “infinito particular", o que me torna ímpar e ao mesmo tempo me faz compreender outros infinitos particulares que me circundam e contribuem na composição do que sou. As interseções que realizo na mediação entre mim e o outro proporciona o entendimento de que o que existe mesmo é diferença como regra e não a exceção, como hegemonicamente vemos difundida no senso comum. Esse entendimento facilita o meu respeito às escolhas, crenças e convicções dos outros sujeitos sem que eu tenha que abrir mão das minhas, desde que eu faça com elas um movimento de análise crítica, que a meu ver podem contribuir para um entendimento ampliado, tanto meu quanto do outro que comigo estabelece relações e vínculos.

A sintese ou roteiro do que abordei em minha tese autobiográfica foi apresentada na tese por um narrador, que é o condutor explicativo da fragmentação do personagem que sou eu. Sob essa perspectiva defendo que o narrador exerce uma função importante para a compreensão, de quem lê sobre o meu mundo, ou em outras palavras, sobre o meu "infinito particular." Reforço que não tive o objetivo de fechar possibilidades interpretativas, produzir fundamentos ou empreender qualquer tentativa de sustentar uma "verdade" ao apresentar uma narrativa autobiográfica. Apenas produzi um discurso, que sob outras óticas poderia encadear outros pontos de vista, inclusive opostos aos que eu apresento. Com o método autobiográfico proposto por Pinar (2007) indico uma sequência, não necessariamente linear, de fatos e vivências minhas e de outros sujeitos com os quais convivi curricularmente e que coloquei sob análise, à luz das teorias pós estruturalistas em consonância com a teoria do discurso político desenvolvida por Ernesto Laclau e Chantal Mouffe.

Cabe informar que entendo currículo pensado como espaço-tempo de fronteira cultural, como defende Macedo (2006), portanto, creio que o currículo se efetiva na negociação entre os sujeitos, suas identidades e na circulação do conhecimento produzida por essa interação, na qual estão presentes as relações de poder, também discursivamente produzidas, o que exige de nós uma reflexão diária sobre os diversos sujeitos que compõem essas relações existentes nas tênues fronteiras entre as culturas presentes no cotidiano escolar e isso exige práticas educativas baseadas no diálogo e interlocução. A partir dessa crença refleti sobre como o currículo entende e lida com as performances de gênero e de sexualidades tão presentes em nossas escolas e como são entendidas as ações políticas que procuram garantir o direito individual e a livre expressão da diversidade de nossa sociedade refletida no espaço escolar.

Escrevi a tese, mais especificamente o segundo capítulo dela, apresentando rubricas, cenas, atos, entreatos, imitando uma escrita teatral, no sentido de tentar propiciar um entendimento das minhas vivências e memórias curriculares. Ou seja, organizei a escrita da tese com um texto no formato que imita um texto teatral que se inicia com um prologo, faz uma apresentação, se subdivide em partes, tem intervalo, faz uma conversa com a plateia 
e termina com uma cortina, que não se fecha.

Por mais que eu vislumbre a impossibilidade de construção de consenso na elaboração de políticas públicas de integração, emancipação e incorporação ampla e digna de milhões de brasileiras/os excluídas/os, direta ou indiretamente, do foco curricular de nossas escolas na segunda dezena do século XXI, acredito que ao evidenciarmos os sujeitos rompentes da norma hegemônica de gênero e sexualidade, estaremos mantendo uma crítica à naturalização da violência e do preconceito contra os indivíduos não heterossexuais.

\section{A autobiografia a partir do método Currere}

Em 2012, no meu primeiro ano do mestrado em educação pelo Programa de Pós-graduação em Educação (PROPED) da Universidade do Estado do Rio de Janeiro (UERJ), me inscrevi em um curso onde tive a oportunidade de conhecer um pouco da obra de Pinar (2011, 2007; 1995) que era o professor convidado da Escola de Altos Estudos, evento que enriqueceu substancialmente as potencialidades de diálogos sobre as perspectivas nos estudos de pós-graduação em educação.

O curso do (PROPED/UERJ) visava a formação acadêmica de pós-graduandos no campo da teoria curricular e para este fim foram criadas duas disciplinas eletivas, uma para doutorado e outra para mestrado com o professor Pinar. Eu era aluno do mestrado e fazia a disciplina Teorias de Currículo com as professoras Alice Lopes e Elizabeth Macedo, organizadoras da Escola de Altos Estudos à época. De ambas recebi, assim como as/os demais alunos/as, o incentivo para participar do curso com um dos principais signatários do movimento da reconceptualização curricular.

Já na primeira aula, no dia 18 de junho daquele ano, cujo tema foi “a reconceptualização dos estudos curriculares: o método currere", comecei a organizar algumas das ideias que só posteriormente, no doutorado, é que consegui materializar ao realizar a escrita da tese como uma narrativa que entrecruza minha biografia como sujeito que ocupa(ou) diversos lugares na vivência curricular. Também trouxe para a conversa autobiográfica as minhas vivências nas artes por considerá-las importantes suportes para o enfrentamento dos preconceitos contra os sujeitos LGBTQ+.

Me apropriei do método de Pinar para desenvolver um texto narrativo sobre minhas experiências na educação, na qual me reconheço como sujeito rompente da "heteronormatividade compulsória" (RICH, 2010) apresentada como hegemonia cultural nas sociedades contemporâneas.

Através da autobiografia identifico-me como sujeito multifacetado, com vivências múltiplas e a partir desta constatação, procurei trazer a discussão sobre as diversas “identidades" vivenciadas por mim (aluno, professor, coordenador pedagógico, diretor e pesquisador) como fios condutores para a abordagem das questões de gênero e sexualidade no cotidiano escolar.

Propus com a tese, a perspectiva de entendimento do currículo como processo que compreenda as identidades como híbridos culturais.

Para dar suporte a esta tarefa, vista como polêmica por muitos sujeitos do "chão da escola," trabalhei com algumas linguagens artísticas, como citei acima, pois a meu juízo elas foram potentes para apresentar, no ambiente escolar, questões consideradas controversas e a partir de uma pesquisa, na qual eu me inseri como participante, defender o que seria um exemplo de currículo "queer"4, ou como prefi-

4 Por mim entendido como uma possibilidade de desconstrução de identidades fixadas e que se apresenta como uma forma de abordar criticamente as identidades. O currículo Queer "falará" a todos e não se dirigi- 
ro designar, um currículo pós-identitário, que pode ser entendido como um currículo aberto para o entendimento de que as identidades não são estanques! Numa perspectiva contrária a essa afirmo que as identidades são construídas culturalmente e recheadas de contradições internas.

\section{Como é descrito o método}

\section{que embasou minha escrita autobiográfica?}

Nas últimas décadas tem se intensificado em diversos países a produção de diversos discursos em defesa da qualidade da educação que justificam a realização de pesquisas que, por meio de diferentes abordagens, buscam analisar, de modo articulado a experiências consideradas exitosas, no que se refere à produção de uma educação de qualidade em diversos contextos. Ortigão e Pereira (MACEDO e MENEZES, 2019, p. 98).

Entendo o significante "qualidade da educação" como um significante vazio ${ }^{5}$, a partir de Laclau (2011), exatamente porque ele abrange um espectro amplo de possibilidades semânticas. Com esse entendimento passei a elencar algumas prioridades para identificar como elementos de promoção da qualidade na educação a integração dos alunos silenciados no currículo por conta de suas expressões de gênero e sexualidade. Encontrei sustentação teórica no método proposto por Pinar.

De acordo com Pinar (1975, p. 19) ${ }^{6}$, o Método Currere "[...] é regressivo-progressivo-analítico-sintético [...]". Em outras palavras é um método, temporal e conceitual por natureza,

rá apenas àqueles ou àquelas que se reconhecem na posição de sujeito da diferença.

5 Para entender esse conceito sugiro a leitura de: Por que os significantes vazios são importantes para a política? In: LACLAU, 2011.

6 As citações da referida obra de Pinar (1975, p. 19-27) foram traduzidas para o português para fins didáticos por Alice Casimiro Lopes e Elizabeth Macedo e estão disponiveis na internet no link: http://www.curriculo -uerj.pro.br/imagens/artigos/programaca_11.pdf. mas objetiva o cultivo de um ponto de vista de desenvolvimento que sugere o "transtemporal e transconceptual" Dito de outra forma, o método é a conceptualização autoconsciente do temporal, é a visão do que foi conceptualizado ao longo do tempo. Então, quando se tem esse entendimento, segundo Pinar, "o que buscamos é explorar a complexa relação entre o temporal e o conceitual" e ao fazermos esse exercício "[...] podemos desvendar a relação com o Self e a evolução com a educação [...]" (1975, p. 19).

Ainda de acordo como Pinar, neste processo importa tentar entender a contribuição que "meus estudos acadêmicos formais dão à compreensão da minha própria vida".

Tomando por hipótese uma situação biográfica, Pinar diz’:

Se, de certa maneira, eu a escolhi (e, portanto, tenho que me responsabilizar por isso), posso também dizer que, de certa forma, ela foi causada em alguma medida por situações prévias. Posso olhar a minha vida de uma maneira linear, reconhecendo seu caráter multidimensional atual, mas limitando minha visão à linearidade para torná-la mais administrável - assim, entendo que isso leva àquilo. $\mathrm{Em}$ uma dada circunstância, eu escolhi isso e rejeitei a alternativa; articulei-me com essas pessoas, depois as deixei por outras; este campo me intrigou, depois este outro; trabalhei neste problema, depois neste outro. Se coloco essas escolhas e circunstâncias em uma linha do tempo e depois começo a descrevê-las (como as lembro agora), as transições dessa situação para as seguintes, vejo que há nelas certa coerência. Não necessariamente uma coerência lógica, mas vivida, sentida. O ponto de coerência é a biografia como vivida: a lebenswelt (PINAR, 1975, p. 20)

Pinar (2007, p. 65) escreve que inventou o método Currere visando percorrer o caminho para sustentar o estudo sistemático da autorreflexão dentro do processo educativo. Segundo o autor, esse método se baseia na forma

7 Registros orais do autor retirados de PINAR (1975) traduzidos por Alice Lopes e Elizabeth Macedo. 
latina do infinitivo de currículo que significa "percorrer um caminho" ou no gerúndio "percorrendo o caminho", o que de acordo com ele, fornece uma estratégia para os alunos de currículo estudarem as relações entre conhecimento acadêmico e história de vida no interesse da auto compreensão e reconstrução social.

Dito de outra forma, o método currere procura entender a contribuição dos estudos acadêmicos para compreensão que cada um tem da sua vida e vice-versa e como ambos estão imbricados na sociedade, na política e na cultura (BRUNER, 1996, apud. PINAR, 2007, p. 66).

Influenciado pela teoria literária feminista currere torna-se uma versão do criticismo cultural. O criticismo cultural, de acordo com Lasch (1983, p. 16):

[...] tomou um caráter pessoal e autobiográfico que no seu pior degenerou em auto exibicionismo, mas que no seu melhor mostrou que a tentativa de compreender a cultura tem de incluir o modo como molda a própria consciência do crítico. (LASCH, 1983)

Devido "aos perigos de exibicionismo de exposição" apontados por De Castell (1999), Pinar afirma que recusou, incialmente, em recomendar o método currere como instrumento instrucional no currículo escolar. Porém, de acordo com o próprio Pinar (2007, p. 66) "o estudioso da experiência pedagógica toma como hipótese que, em qualquer determinado momento ele está numa situação biográfica". TrabaIhando com sua própria autobiografia, Pinar (1995, p. 520, citando Pinar e Grumet," escreve:

Consigo perceber que isto me leva àquilo; nessa circunstância escolhi aquilo, rejeitei esta alternativa; associei-me àquelas pessoas, depois deixei-as por estas, que este campo me intrigou intelectualmente, depois aquele; trabalhei neste problema depois naquele... Vejo que há uma coerência. Não necessariamente uma coerência lógica, mas uma coerência vivida, uma coerência sentida. 0 propósito da coerência é a biografia como ela é vivida... A [questão] predominante é: qual foi e qual é, agora, a natureza da minha experiência educativa? (PINAR; GRUMET, 1976, p. 52)

Pinar (1975, p.20) faz uma grande quantidade de questionamentos sobre esta possibilidade metodológica. Dentre os principais, há um que entendo como primordial, que é: "o que tem sido e é hoje a natureza de minha experiência educacional?".

\section{Outras inspirações}

Outra forte inspiração de narrativa autobiográfica me foi dada quando li o livro "Nas malhas da diferença: nuanças de gênero na educação de crianças", de Marta Regina Alves Pereira (2005) durante a escrita da monografia que apresentei para concluir a especialização lato sensu, em currículo, que fiz na Faculdade de Educação da Universidade Federal Fluminense. $\mathrm{Na}$ apresentação de seu texto Marta indica suas vivências e a importância delas para as escolhas teóricas que ela havia feito ao realizar uma pesquisa, também com questões de gênero e sexualidade, no chão da escola. A partir daquela influência consegui fazer um mergulho em minha memória e recordar fatos que agora podem ser melhores entendidos ou até mesmo ressignificados.

De acordo com Abrahão:

[...] as (auto)biografias são constituídas por narrativas que desvelam trajetórias de vida. Esse processo de construção tem na narrativa a qualidade de possibilitar a autocompreensão, o conhecimento de si, àquele que narra sua trajetória. $(2004$, p. 204)

Apesar da constatação de que no mundo contemporâneo a experiência comunicável entrou em baixa (BENJAMIM, 1994), a narrativa autobiográfica retoma o centro do palco quando 
temos a pessoa e as ações do humano como foco de conhecimento. É o que diz Nóvoa:

Durante muito tempo o mundo foi visto como estrutura e como representação. impõe-se agora, vê-lo também como experiência, o que obriga a invenção de uma nova epistemologia do sujeito. Olhando para os livros escritos nas últimas décadas surge de imediato a questão: onde é que estão as pessoas? $(2004$, p. 9)

Segundo aponta Wolney Honório Filho: “a autobiografia é uma forma de ver o mundo como experiência que atente para os relatos de vida, que a reorganiza em função de novos objetivos, de novos desafios" (2011, p. 194)

Estes desafios estão dados na nossa condição de sujeitos em constante movimento de auto recriação. $O$ autor diz mais, citando Santos (2009, p. 24): “[...] olhar para os testemunhos (história de vida), dentro de um padrão racional científico seria desconfiar da experiência imediata".

Mas o problema não são as histórias de vida e sim a maneira de encará-las cientificamente. Para Honório Filho (2011) a abordagem autobiográfica muda o eixo do conhecimento das coisas, não o desprezando para conhecer quem conhece as coisas, ou seja, as pessoas. Essa é uma possibilidade, conhecer as pessoas: tanto os outros, numa perspectiva de alteridade, quanto a nós mesmos como nos diz Santos (2009): "todo conhecimento é autoconhecimento", portanto, entendo que se faz necessário enfrentar esse desafio de conhecer pessoas no projeto formativo possibilitando que elas também se conheçam mais e melhor.

Nesse propósito revisitei "vivências" e identifiquei um método para contar uma história. Com ele me reconheci como criança que brincava no recreio da escola! Percebi-me adolescente e senti "na pele" (e principalmen-

8 Pós-Doutor em Educação pela Pontifícia Universidade Católica do Rio Grande do Sul e Professor do curso de Pedagogia da Universidade Federal de Goiás - Campus Catalão (GO - Brasil) te na alma) os preconceitos; reencontrei-me com as experiências vividas como aluno do Ensino Fundamental e Médio (curso normal), no qual fui habilitado a ser professor "primário" para dar aulas da primeira a quarta séries (atualmente primeiro ao quinto ano do Ensino Fundamental). Rememorei que após essa formação, me aproximei das artes cênicas, pois, à época, desejava me profissionalizar como ator, uma vez que já fazia essa atividade de forma amadora desde que, na escola, tive contato com a representação teatral.

Imbuído do desejo de reconhecer minha historiografia, o método ajudou-me a evidenciar que após um afastamento de cinco anos realizei meu reencontro com a educação, que se deu, de novo na condição de estudante, quando comecei a cursar a graduação em letras (português/literaturas) na Universidade Federal Fluminense no ano de 1997 e posteriormente na condição de professor dos primeiros anos do Ensino Fundamental, ao me tornar docente efetivo da rede municipal do Rio de Janeiro, para onde entrei no ano 2000, por concurso público e que depois de nove anos como docente, tornei-me coordenador pedagógico de uma escola municipal e que para entender melhor o que era coordenar o programa pedagógico daquela unidade escolar, resolvi continuar meus estudos de pós graduação iniciados com o curso de especialização lato sensu em currículo, no programa de Pós-graduação em Educação da Faculdade de Educação da Universidade Federal Fluminense.

O método autobiográfico me fez identificar as memórias iniciais dos estudos curriculares, que fiz, como já expliquei, para coordenar a construção coletiva do Projeto Político Pedagógico (PPP) da escola em que eu exercia a função de Coordenador Pedagógico e reconheço a importância de ter colocando na pauta das discussões o respeito às diferenças representadas pelos alunos "rompentes" da 
hegemonia heteronormativa, ou seja, o método sinaliza que fui responsável pela inclusão das questões de gênero e sexualidade no currículo vivido no cotidiano daquele ambiente escolar.

Foi também o método autobiográfico que me ajudou a recontar outros percursos nos estudos de pós graduação, quando no ano de 2011 concluí a especialização e participei do processo seletivo para o ingresso no mestrado do programa de Pós-graduação em Educação da Universidade do Estado do Rio de Janeiro, no qual fui aprovado e concluído no ano de 2014, com a defesa da dissertação Questões de gênero e sexualidade no currículo escolar, mesmo ano em que realizei o processo seletivo e entrei para o doutorado, concluído em maio de 2019 com a defesa de tese Narrativa autobiográfica: inscrevendo minha(s) identidade(s) na cena curricular.

\section{Identificando a autobiografia a partir do método currere como objeto de pesquisa}

Percebendo que toda a minha pós-graduação, incluindo os anos do doutorado, foi feita na área de Educação, em estudos curriculares e que, desde a especialização lato sensu, tenho estudado as questões de gênero e sexualidade na escola, resolvi, apoiado na perspectiva de Pinar (2007), Benjamim (1994), Abrahão (2004), Nóvoa (2004) e Pereira (2005), rememorar minhas vivências e pesquisas realizadas na área para apontar um exemplo de experiência curricular que reconhecesse efetivamente a abordagem dessas questões. É importante ressaltar que as memórias e os estudos se entrecruzam na narrativa autobiográfica que fiz, cujo objetivo foi experimentar possibilidades de inclusão, nas discussões curriculares e nas ações pedagógicas, das questões de gênero e sexualidade entendidas como garantidoras da equidade de direitos entre alunos heterossexuais ou homossexuais.

Através de uma autobiografia procurei narrar não apenas as experiências, mas também os sentidos envolvidos nessas experiências, incluindo os que estiveram presentes nas arenas de disputas discursivas. Realizei análises desses discursos com os diferentes sujeitos neles envolvidos: professores, alunos, equipes gestoras, pais e responsáveis e também apresentei, de forma sucinta, um pouco da conjuntura política mundial e brasileira da atualidade, que considero como de retrocessos, refletidos na tentativa de marginalização das questões de gênero e sexualidade, por iniciativas como as do Movimento Escola sem Partido e de outros projetos conservadores que têm procurado influenciar a cultura escolar no que tange às discussões de gênero e sexualidade, ensejando uma diminuição de políticas públicas para a população LGBTQ+.

Relatei, na tese, a experiência que tenho tentado organizar - como diretor de uma escola do município do Rio de Janeiro - de um currículo numa perspectiva mais inclusiva das demandas dos alunos que rompem com a heteronormatividade e nesse processo narrei vivências de alunos que são descritos, não como exemplos de vitimização, mas como paradigmas de superação dos preconceitos e marginalidades geralmente ainda muito presentes no cotidiano de nossas escolas.

As questões de gênero e sexualidade no currículo também serviram para descortinar a minha própria existência enquanto sujeito que também venceu preconceitos e estigmas e que agora procura ampliar esta perspectiva de superação para outros sujeitos.

Atento às indagações dos autores que utilizam a autobiografia como instrumento de pesquisas, em particular as de Pinar $^{9}$, in-

9 Que ministrou um curso na Escola de Altos Estudos, do Programa de Pós-graduação em Educação da Universidade do Estado do Rio de Janeiro no ano 2012. 
corporo a hipótese de que, mesmo não tendo respostas para elas, a relação entre meu trabalho profissional e meu trabalho pessoal se entrecruzam com minhas vivências e tudo isso se apresenta como fonte de dados. De acordo com a crença de Pinar, o método de geração dos dados é como a técnica psicanalítica da livre associação.

Se eu escrever sobre minha situação biográfica como eu a vejo (não como a gostaria de ver, ainda que isso possa estar incluído), será como se eu tivesse escapado dela. Está lá, de alguma forma, no papel e continuo aqui, na máquina de escrever, olhando para o impresso e para a conceptualização de uma perspectiva que era minha e, portanto, o lugar é novo ${ }^{10}$. (PINAR, 2012)

Por que estou envolvido nesse projeto de pesquisa que me ocupa agora? Esta questão particular, conforme salienta Pinar, reforça a crença de que, trabalhando a maneira como vou descrever é que me levará a obter a informação que me moverá biograficamente, não apenas de forma linear, mas através de uma perspectiva multidimensional.

Ao se referir à temporalidade biográfica, Pinar diz:

O passado biográfico existe no presente, contribuindo de forma complexa para o presente biográfico. Quando dizemos que ele não pode ser considerado responsável pelo presente, a extensão com que ele é ignorado é provavelmente a extensão com que ele é responsável pelo que é o presente ${ }^{11}$. (PINAR, 2012)

Tratando da espacialidade e da temporalidade a ela aliada, o professor Pinar (1975) registra:

Para o sujeito definir onde está e quando está,

10 Transcrição de aula proferida em 2012, na Universidade do Estado do Rio de Janeiro, Escola de Altos Estudos, realizada pelo Programa de Pós-graduação em Educação.

11 Transcrição de aula proferida em 2012, na Universidade do Estado do Rio de Janeiro, Escola de Altos Estudos, realizada pelo Programa de Pós-graduação em Educação. ele precisa localizar o passado. Localizar significa identificação, significa colocar o passado entre parênteses. Colocar entre parênteses significa olhar para o que não é normalmente visto, para o que é tomado como dado, consequentemente se afastando dele. Como o passado se torna, o presente é revelado. $(1975$, p. 23)

De acordo com o que se pode inferir da proposição teórica abordada por Pinar, quando isso ocorre, objetiva-se tanto a liberdade do passado quanto a liberdade do presente. Esse é o ponto da primeira fase do método currere: observar-se no presente funcionando no passado.

Como o foco do método é a experiência educacional, o sujeito deve reconhecer sua vida passada na escola, sua vida passada com professores, livros e outros artefatos escolares e para isso ele deve observar e gravar. Deve também inclui respostas presentes para o que é observado. Pinar chega a sugerir a ideia de que o sujeito realizador de uma autobiografia retorne para o início da escolarização, para os anos iniciais, ou para onde ele for capaz de chegar.

Ele propõe que realizadores desse método, devem "entrar"12 de novo na sala de aula, assistir os professores, a si e a seus colegas, refletir sobre ações e orienta:

Não tente interpretar o que você observa neste momento. Interpretação interrompe a presença no passado. Vá dos primeiros anos ao nível médio, mantendo o foco do observador em si próprio. 0 self, na sala de aula, como aquele(a) professor(a), aqueles assuntos, aquela resposta para aquele(a) professor(a), a intervenção dos pais em relação àquela situação e a resposta do sujeito. A ligação do sujeito com esses assuntos e aqueles professores; o desinteresse do su-

12 Esse movimento não é literal, é de imersão no passado, entretanto, penso que possa ser estimulado pela visita a ambientes que facilitem essas memórias, como ida a uma escola onde esta/e biografa/o tenha estudado e agora, como observador, assista aulas de turmas com idade equivalente à de sua memória do passado vivido naquele local. 
jeito por este campo, o desagrado com esse(a) professor(a). Esse colégio ou aquele? O self em meio a isso tudo, expandindo-se dessa forma, deixando esses amigos, iniciando uma amizade com aqueles, tendo esses interesses acadêmicos e depois aqueles. Durante a graduação. Esses cursos, aqueles professores. Esses amigos. Que sequência? Outono. Inverno. Primavera. Trabalhos de verão. Fazendo esses cursos. Estudando na biblioteca, tentando estudar no dormitório. Essa garota, aquele amigo, a guerra, raiva, ódio. Ficando acordado ou, principalmente, pensando-se acordado e sabendo, mas nem acordado nem sabendo, sempre pensando, o corpo fisico frequentemente ausente. A principal área de interesse finalmente escolhida. Para a graduação. Graduação e trabalho como professor. Reuniões profissionais. 0 momento presente. A vida dos sujeitos, sua vida educacional, sua vida nas escolas ${ }^{13}$. (PINAR, 2012)

A partir do entendimento proposto pela tradução dos escritos de Pinar, o sujeito "reentra na sua própria história; volta; regride; o lá é aqui, no presente", ou seja, o biógrafo de si mesmo "traz o passado para o presente por sua impressão." Dessa forma o autor define que esse é o primeiro passo do procedimento, ou dito de outro modo, é a regressão ao passado e o retorno ao presente.

Pinar (2007, p. 67, citando PINAR e GRUMET, 1976 p. 55) descreve o primeiro movimento do método, ou momento regressivo concebendo - o como a experiência aparentemente passada "vivida" ou existencial como "fonte de dados" e que, para gerar "dados", fazem-se associações livres, através da técnica psicanalítica para entrar no passado e a partir daí alargar e transformar - a própria memória. Ao fazê-lo, retrocede-se, "volta-se ao passado, para perceber como este foi e como (ele) paira sobre o presente".

A próxima fase do método currere é o mo-

13 Transcrição de aula proferida em 2012, na Universidade do Estado do Rio de Janeiro, Escola de Altos Estudos, realizada pelo Programa de Pós-graduação em Educação. vimento Progressivo. Progressivo deriva do pro, significando "antes" e gradi significando "andar, ir". Nessa fase, olhamos no outro sentido. Olhamos, na linguagem de Sartre, para o que ainda não é o caso, o que ainda não é o presente. Achamos que o futuro é presente da mesma maneira que o passado é presente. Isso influencia de maneira complicada o presente; isso forma o presente.

Pinar (1975) indica a experiência descrita abaixo:

Sente-se sozinho, talvez num quarto ligeiramente escuro, numa cadeira confortável com um suporte para escrever e uma caneta. Feche os olhos, preste atenção na sua respiração. Respire lentamente algumas vezes, porque isso é reconfortante. $O$ sentido desses minutos é o relaxamento. Depois de relaxado, o sujeito pensa no futuro, no amanhã, na próxima semana, nos próximos meses, no próximo ano acadêmico, nos próximos três anos e daí por diante. Como nosso interesse é a experiência acadêmica, lentamente torne a dar atenção para assuntos associados aos seus interesses intelectuais e permita que sua mente trabalhe por livre associação. Grave o que surge. Tente discernir onde seus interesses intelectuais estão indo, a relação entre a evolução desses interesses e a sua vida privada, entre esses dois e o desenvolvimento das condições históricas. Possivelmente, você vai ver algo da natureza interdependente entre os seus interesses e a situação histórica. Se você é um(a) professor(a), foque no seu trabalho, na sua relação com os alunos e com os colegas, especialmente no conteúdo emocional disso, assim como no conteúdo intelectual. Procure discernir onde isso parece estar indo. Você deve imaginar um futuro, quem sabe um ano à frente ou alguns anos; descreva isso. (É importante no momento progressivo, assim como no regressivo, associar livremente, evitando usar aspectos racionais, lógicos e críticos. Não conclua, por exemplo, que um estado futuro imaginário não é razoável. Neste estágio, permita visões normalmente apagadas do que ainda não está presente para se manifestar). Faça isso enquanto se sentir confortável, quando ocorrer resistência, anote sua qualidade e conteúdo. 
Não force o processo. Volte a cadeira e a esse contato com estados de futuro imaginado algumas vezes em dias diferentes por um período de alguns dias, semanas ou meses. (PINAR, 1975, p. 24)

De acordo com a tradução de Pinar (1975, p. 24.) "[...] essa ampliação do experimento reduz a possibilidade de distorção por preocupações temporárias [...]". Isso seria o processo da progressão. Portanto, nesse segundo passo ou momento progressivo olha-se, para o que ainda não é o caso, o que ainda não é presente. "Como o passado, sugere, o futuro reside no presente". O autor entende que, meditativamente, o estudioso do método currere imagina futuros possiveis.

O passo seguinte é o momento Analítico.

$\mathrm{Na}$ fase analítica, o estudioso examina tanto passado quanto o presente. Etimologicamente ana ${ }^{14}$ significa "até, através" lusis significa "uma libertação". A análise de currere é semelhante a um agrupamento fenomenológico; a distanciação de cada um dos fatos do passado e do futuro funciona de maneira a criar um espaço subjetivo de liberdade no presente. Isto ocorre no momento analítico: "Como é que o futuro está presente no passado, o passado no futuro, e o presente em ambos? (PINAR, 2007, p. 67).

Ao fazer uma analogia dos passos anteriores do método com fotografias tiradas, reveladas e reservadas, Pinar crê que o sujeito da autobiografia se indague sobre o que falta e encontre como resposta a descrição do presente biográfico, excluindo o passado e o futuro, mas incluindo as respostas a eles.

Para muitos, o presente está misturado no tecido da vida institucional. Dentro dessa forma histórica, concretamente incorporada às materialidades, o sujeito autobiográfico pergunta: o que é o seu presente? Quais são os seus interesses intelectuais? O que é a con-

14 NT - Do Grego, análusis significa dissolução (por oposição a síntese) - Dicionário Houaiss da Língua Portuguesa. dição emocional? Por quais ideias, áreas de estudo, disciplinas ele é capturado? E o que o repele?

Pinar sugere que se faça uma lista dessas atrações/retrações, mas chama a atenção para a necessidade de não as interpretar, apenas descrevê-las.

Novamente fazendo analogia entre 0 ato de "fotografar" (registrar) e o resultado da revelação (interpretação) Pinar indica:

Fotografe o presente como se o sujeito fosse uma câmera, incluindo-se no presente da fotografia, assim como sua resposta a esse processo. Colocando entre parênteses o que é, o que foi, o que pode ser, o sujeito está se despregando da experiência, está potencialmente mais livre dela, portanto mais livre para livremente escolher o presente, o futuro. Estude as três fotografias. 0 que elas são, o que é sua individualidade? Que temas biográficos fundamentais eles expressam? Por que elas são como são? A interpretação deve tornar mais visível o que é diretamente vivido. A interpretação não deve subordinar o presente vivido a uma grade analítica e abstrata. A análise que o sujeito faz é um elemento constituinte do presente, como o cérebro é uma parte do corpo e não o corpo é pensamento no cérebro. (PINAR, 2012) ${ }^{15}$

De acordo com Pinar (2007, p.67) “[...] a fase analítica não é auto escrutínio pelo bem do desempenho público, uma auto teatralização em que a vida social se transforma em espetáculo." Pinar (op.cit.) esclarece, então, que o propósito do método currere é um compromisso intensificado com a vida diária, não seu afastamento irônico.

Como está o futuro presente no passado, o passado no futuro e o presente em ambos? 0 presente biográfico justapõe as três "fotografias": passado, presente, futuro, para investigar quais são suas inter-relações complexas e multidimensionais? - Pergunta Pinar apontan-

15 Transcrição de aula proferida em 2012, na Universidade do Estado do Rio de Janeiro, Escola de Altos Estudos, realizada pelo Programa de Pós-graduação em Educação 
do para a última fase de seu método autobiográfico que é a síntese.

o que é essa complexidade temporal que se apresenta como um momento presente no momento sintético

Sintético. Sys significa "junto" e tithenai significa "colocar", "localizar", centra-se no presente vivido. Consciente de sua própria respiração e do fato de reconhecer sua própria alteridade personificada, pergunta-se: “Quem é aquele?" De acordo com Pinar (2007, p. 68) "ouvindo cuidadosamente a sua própria voz interior no mundo histórico natural, perguntase: Qual é o significado do presente?"

A última fase desse método, a síntese, está baseada na crença de que o Self é acessivel ao sujeito em sua forma física. 0 intelecto, residindo em forma física, é parte do Self, portanto, para Pinar (1975, p. 26): “O Self não é um conceito que o intelecto tem de si. 0 intelecto é um apêndice do Self, um meio, como o corpo, através do qual o Self e o mundo são acessíveis para eles.".

Com a mente em seu lugar, o sujeito conceptualiza a situação presente e chega à conclusão de que está localizado junto.

\section{Considerações finais sobre o método autobiográfico, indivíduo, cultura e currículo}

Segundo Pinar (2007, p. 69) “[...] a autobiografia é uma visão singular e na primeira pessoa da cultura e da história como elas estão personificadas no indivíduo concretamente existente na sociedade e no período histórico." O autor a partir dessa constatação questiona: "como seria o currículo se centrássemos as disciplinas escolares nas histórias e reflexões autobiográficas daqueles que as suportam?"

Respondendo à própria indagação o autor afirma que "[...] os assuntos, nas disciplinas escolares referir-se-iam tanto em assuntos hu- manos quanto em assuntos acadêmicos".

De acordo com Pinar (op. cit, p, 69) “[...] a política cultural não pode ser conduzida, nessa altura, neste lugar, sem uma política do indivíduo e, dentro dessa esfera subjetiva, o próprio indivíduo deve ser um ativista a trabalhar no sentido de democratizar a interioridade de cada um." Sustentando esse entendimento, o autor defende que a população interiorizada intimamente, ou seja, as diversas vozes internas compõem o eleitorado, por assim dizer, da constituição identitária que fazemos aparecer e essa população interior tem que ser reconhecida, respeitada, persuadida e não silenciada, “deportada sem audiência" (PINAR. 2007, p. 69) para fora dessa construção cultural da identidade subjetiva. Com isso Pinar acredita que somente através de uma democratização genuína dos elementos interiorizados de cada um, na qual nenhum sujeito é deportado (projetado em termos psicanalíticos) para os corpos dos outros é que, então, se compreenderá a alteridade.

A tarefa educativa, conforme a convicção de Pinar, é pegar nas manchetes que nós contamos a nós próprios e olhar para as páginas de trás. Temos de ensinar aquilo que as manchetes tentam esconder, ou seja, temos que expor e problematizar aquilo que o currículo pode ocultar. 0 autor do método currere salienta que o que se objetiva, ao fim e ao cabo, não é romantizar as pessoas marginalizadas, ainda que segundo ele haja motivos para admirá-las, mas, entender que o outro é, geralmente, construido a partir das nossas fantasias e isso pode não ser benéfico.

Pinar sugere, então, que o sujeito realizador da autobiografia olhe para si concretamente, como se fosse num espelho e chama atenção à respiração, para sublinhar a concretude biológica do ser.

De acordo com o que sustenta Pinar, ao prescrever esse método, o sujeito autobiogra- 
fado deve fazer uma relação com a sua forma de vida. Isso inclui suas vidas pública e privada, seus comportamentos externamente observáveis e o conteúdo do seu fluxo de consciência. o corpo físico pode ser uma manifestação concreta de tudo o que ocorre nele e através dele.

o método currere reconceptualizou o currículo com objetivos para uma conversação complexa consigo próprio (como um intelectual "privado"), num projeto contínuo de auto compreensão, no qual cada um se mobiliza para ação pedagógica comprometida como intelectual privado e público, com os outros sujeitos na reconstrução da esfera pública.

A teoria do currículo pede ao professor prospectivo ou praticante que considere a sua posição enquanto comprometido consigo próprio, com seus alunos e com colegas na construção de uma esfera pública, uma esfera pública ainda não nascida, um futuro que não pode ser discernido no presente, ou mesmo, pensado a partir dele. Assim concebida a sala de aula torna-se, simultaneamente, um quadrado cívico e democrático, mas também um "espaço só seu", ou seja, de afirmação de sua identidade e de sua subjetividade.

\section{Referências}

ABRAHÃO, Maria Helena Menna Barreto. Pesquisa (auto)biográfica - tempo memórias e narrativas. In. ABRAHÃO Maria Helena Menna Barreto. (Org.) A aventura (auto)biográfica: teoria \& empiria. Porto Alegre EDIPUCRS, 2004. p. 201- 224.

BENJAMIN, Walter. 1892 -1940. Magia e técnica, arte e política: ensaios sobre literatura e história da cultura / Walter Benjamin; tradução Sergio Paulo Rouanet; prefácio Jeanne Marie Gagnebin. - 7. ed. - São Paulo: Brasiliense, 1994. - (Obras escolhidas; v.1)

DE CASTELL, Suzanne. On finding one's lace in the text: Literacy as a tecnology of self-formation. In: WILLIAM F. Pinar (Ed.) Contemporay curriculum discourses: tweny years of JCT (398-411). New York: Peter Lang. 1999. p. 398-411.
HONÓRIO FILHO, Wolney. Velhas histórias coladas à pele: a importância das histórias de vida na formação do professor. Educação, Porto Alegre, v. 34, n. 2, p. 189 -197, 2011.

LACLAU, Ernesto. Emancipação e diferença. Coordenação e revisão técnica geral Alice Casimiro Lopes e Elizabeth Macedo. Rio de Janeiro: EdUERJ, 2011.

LASCH, Christopher. A cultura do narcisismo. Rio de Janeiro: Imago Ed., 1983.

MACEDO, Elizabeth. Currículo como espaço-tempo de fronteira cultural. Revista Brasileira de Educação, Rio de Janeiro, v. 11, n. 32, p. 285-372, mai/ago, 2006. Disponivel em: http://www.scielo.br/scielo. php?pid=S1413-24782006000200007\&script=sci_arttext\&tlng=pt Acessado em: 10 set. 2019.

MACEDO, Elisabeth; MENEZES, Isabel. (Org.) Currículo, Política e Cultura. Conversas entre Brasil e Portugal. Curitiba: Editora CRV, 2019.

NÓVOA. Antônio. Prefácio. In: ABRAHÃO, Maria Helena Menna Barreto (Org.) História e histórias de vida: destacados educadores fazem a história da educação rio grandense. 2. ed. Porto Alegre: EDIPUCRS, 2004. p. 7-12.

$\mathrm{RICH}$, Adrienne. Heterossexualidade compulsória e existência lésbica. Revista Bagoas, Natal, UFRN, n. 5, p. 17-44, 2010. Disponivel em: https://periodicos. ufrn.br/bagoas/article/view/2309/1742 Acessado em: 15 set. 2019.

ORTIGÃO, Maria Isabel Ramalho; PEREIRA, Talita Vidal. Trabalho Colaborativo: conflito e dialogicidade. In: MACEDO, Elisabeth; MENEZES, Isabel. (Org.) Currículo, Política e Cultura. Conversas entre Brasil e Portugal. Curitiba: Editora CRV, 2019. p. 95-109.

PEREIRA, Marta Regina Alves. Nas malhas da diferença: nuanças de gênero na educação de crianças. Uberlândia: EDUFU, 2005.

PINAR, William F. The method of currere (1975). In: PINAR, William F. (Ed). Autobiography, Politics and Sexuality. New York: Peter Lang, 2011. p.19-27.

O que é a teoria do currículo? Porto:

Porto Editora. 2007. 
et al. Understanding curriculum. New

York: Peter Lang, 1995.

PINAR, William F. and GRUMET, Madeleine R. Toward

a poor curriculum. Dubuque, IA: Kendall/Hunt. 1996.
SANTOS, Boaventura de Sousa. Um discurso sobre as ciências. 6. ed. São Paulo: Cortez, 2009.

Recebido em: 29.09.2019

Aprovado em: 26.03.2020

Hiller Soares Santana é Doutor em Educação pelo Programa de Pós-graduação em Educação da Universidade do Estado do Rio de Janeiro. Docente do quadro efetivo da prefeitura da cidade do Rio de Janeiro e atualmente Diretor da Escola Especial Municipal Francisco de Castro. E-mail: hiller.lyn@gmail.com 